\title{
Neuromuscular Blocking Property of Minocycline in the Rabbit
}

\author{
Yasuhiko Hashimoto, Takeshi Shima, Shuh Matsukawa \\ and Kenichi Iwatsuki* \\ Department of Anesthesiology, Tohoku University School of \\ Medicine, Sendai 980
}

\begin{abstract}
Hashimoto, Y., Shima, T., Matsukawa, S. and Imatsuki, K. Neuromuscular Blocking Property of Minocycline in the Rabbit. Tohoku J. exp. Med., 1979, 129 (2), 203-204 - The neuromuscular blocking property of minocycline hydrochloride (MNC) was studied in 12 rabbits. In 2 of 6 animals, MNC, 60-160 $\mathrm{mg} / \mathrm{kg}$, alone caused a decrease in twitch tension. During partial neuromuscular blockade produced by a continuous infusion of pancuronium, the intravenous administration of $\mathrm{MNC}, 20-60 \mathrm{mg} / \mathrm{kg}$, resulted in a dose-dependent decrease in twitch tension in 6 animals. MNC-induced or combined MNC-pancuronium. induced neuromuscular blockade was antagonized by calcium or by neostigmine. minocycline; neuromuscular transmission
\end{abstract}

Prolonged neuromuscular blockade is a well-known adverse effect that follows administration of antibiotics. The tetracycline group of antibiotics producing neuromuscular blockade includes tetracycline, oxy-tetracycline, and roli-tetracycline (Pittinger et al. 1970). Minocycline hydrochloride (MNC) is structurally related to the tetracycline group of antibiotics. The effects of MNC on the neuromuscular transmission have not been reported. Therefore, this study was undertaken to examine the neuromuscular blocking properties of MNC in the rabbit.

\section{Methods}

Twelve rabbits weighing 2.4-3.4 $\mathrm{kg}$ were anesthetized with pentobarbital, $30 \mathrm{mg} / \mathrm{kg}$, intravenously. A tracheostomy was performed and ventilation was controlled mechanically to maintain $\mathrm{PaCO}_{2}$ in the range of $35-45$ torr. A carotid artery was cannulated for blood pressure monitoring and sampling. The external jugular veins were cannulated for fluid and drug administration. The left tibialis anterior tendon was cut and secured to a Shinko U-gage force-displacement transducer. The peroneal nerve was stimulated through platinum electrodes using a Nihon Kohden SEN-1101 stimulator and a stimulus isolation unit with supramaximal square waves of $0.2 \mathrm{msec}$ duration. The electrical stimuli were applied either continuously with $0.2 \mathrm{~Hz}$ or with $2 \mathrm{~Hz}$ for $2 \mathrm{sec}$. In the latter case, train-of-four ratio was expressed as percentage of the ratio of the 4 th response to the first. Isometric twitch tension and arterial blood pressure were recorded on a Nihon Kohden polygraph.

When a steady twitch tension was obtained, the rabbits were randomly divided into 2 groups. In group I of 6 rabbits, the initial dose of MNC (Japan Lederle), $20 \mathrm{mg} / \mathrm{kg}$, was administered as an intravenous bolus. The additional increments of MNC, $20 \mathrm{mg} / \mathrm{kg}$, were given in order to study the responses to 100 to $180 \mathrm{mg} / \mathrm{kg}$ of the drug. In 6 other animals, pancuronium bromide was dissolved in normal saline solution and administered

Received for publication, March 10, 1979.

* Emeritus Professor. 
intravenously by a continuous infusion to produce a constant $65-70 \%$ twitch tension of the control. Then, MNC, $20 \mathrm{mg} / \mathrm{kg}$, was administered intravenously. When maximal effects were obtained, additional increments of MNC were given to produce cumulative doses of 40 and $60 \mathrm{mg} / \mathrm{kg}$. The antagonizing effeets of neostigmine sulfate and calcium chloride were also studied.

\section{Results and Discussion}

MNC, $100-180 \mathrm{mg} / \mathrm{kg}$, alone did not depress twitch tension in 4 of 6 animals. In 2 animals, the intravenous administration of $\mathrm{MNC}, 60-160 \mathrm{mg} / \mathrm{kg}$, caused a decrease in twitch tension. Dose-dependent reduction was found in twitch tension when MNC, $20-60 \mathrm{mg} / \mathrm{kg}$, was given intravenously during partial neuromuscular blockade produced by a continuous infusion of pancuronium (Fig. 1). MNC-induced or combined MNC-pancuroniuminduced blockade was antagonized by neostigmine or by calcium.

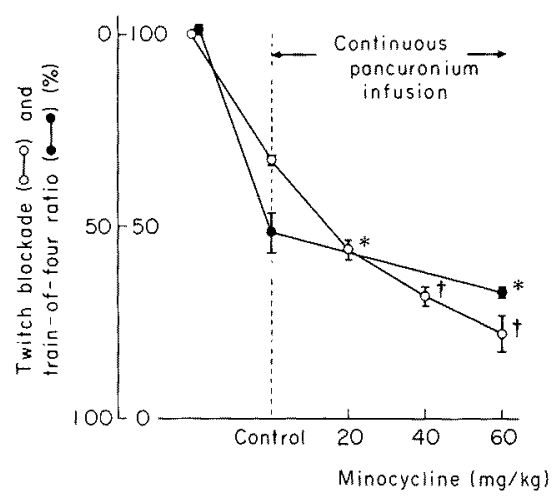

Fig. 1. The changes in twitch tension and train-of-four ratio (mean \pm s.E.) when minocycline hydrochloride, $20-60 \mathrm{mg} / \mathrm{kg}$, was given intravenously during a continuous pancuronium infusion. ${ }^{*} p<0.01, \dagger p<0.001$ compared with values for control.

The main pharmacologic mechanism of neuromuscular blockade by the tetracycline group of antibiotics is to inhibit acetylcholine release from nerve endings possibly by chelation of calcium (Pittinger and Adamson 1972). Our results suggest that the characteristics of neuromuscular blocking properties of MNC may well be similar to those of other members of the tetracycline group.

The dosage of MNC used in this study greatly exceeded the therapeutic ranges. Several clinical situation, however, may produce possible neuromuscular blockade due to overdosage or due to interaction with non-depolarizing muscle relaxants. Since the major excretion route of MNC is urinary, renal failure may increase the blood levels of the drug. The neuromuscular blockade is expected to be more pronounced in a patient with myasthenic state (Hashimoto et al. 1977).

In conclusion, the potential clinical hazard as revealed by this study lies in the sequence of administration of MNC.

\section{References}

1) Hashimoto, Y., Sasaki, H., Yoshinari, M. \& Iwastuki, K. (1977) Myasthenia gravis and antibiotics. Jpn. J. Anesthesiol., 26, 143-148.

2) Pittinger, C. \& Adamson, R. (1972) Antibiotic blockade of neuromuscular function. Ann. Rev. Pharmacol., 12, 169-184

3) Pittinger, C., Eryasa, Y. \& Adamson, R. (1970) Antibiotic induced paralysis. Anesth. Analg. (Clev.), 49, 487-501. 